\title{
Age-related cognitive impairments in mice with a conditional ablation of the neural cell adhesion molecule
}

\author{
Reto Bisaz, ${ }^{1,4}$ Pere Boadas-Vaello, ${ }^{1,2,3,4}$ David Genoux, ${ }^{1}$ and Carmen Sandi ${ }^{1,5}$ \\ ${ }^{1}$ Laboratory of Behavioral Genetics, Brain Mind Institute, Ecole Polytechnique Federale de Lausanne (EPFL), 1015 Lausanne, \\ Switzerland; ${ }^{2}$ Department of Psychobiology and Methodology of Health Sciences, Institute of Neuroscience, Universitat Autonoma de \\ Barcelona, 08193 Barcelona, Spain; ${ }^{3}$ NEOMA Research Group, Department of Medical Sciences, Faculty of Medicine, Universitat de \\ Girona (UdG), 17071 Girona, Spain
}

\begin{abstract}
Most of the mechanisms involved in neural plasticity support cognition, and aging has a considerable effect on some of these processes. The neural cell adhesion molecule (NCAM) of the immunoglobulin superfamily plays a pivotal role in structural and functional plasticity and is required to modulate cognitive and emotional behaviors. However, whether aging is associated with NCAM alterations that might contribute to age-related cognitive decline is not currently known. In this study, we determined whether conditional NCAM-deficient mice display increased vulnerability to age-related cognitive and emotional alterations. We assessed the NCAM expression levels in the hippocampus and medial prefrontal cortex (mPFC) and characterized the performance of adult and aged conditional NCAM-deficient mice and their age-matched wild-type littermates in a delayed matching-to-place test in the Morris water maze and a delayed reinforced alternation test in the T-maze. Although aging in wild-type mice is associated with an isoform-specific reduction of NCAM expression levels in the hippocampus and mPFC, these mice exhibited only mild impairments in working/episodic-like memory performance. However, aged conditional NCAM-deficient mice displayed pronounced impairments in both the delayed matching-to-place and the delayed reinforced alternation tests. Importantly, the deficits of aged NCAM-deficient mice in these working/episodic-like memory tasks could not be attributed to increased anxiety-like behaviors or to differences in locomotor activity. Taken together, these data indicate that reduced NCAM expression in the forebrain might be a critical factor for the occurrence of cognitive impairments during aging.
\end{abstract}

[Supplemental material is available for this article.]

One of the hallmarks of normal aging is a gradual decline in cognitive function associated with the progressive reduction of structural and functional plasticity in brain regions that play a key role in cognitive functions, such as the hippocampus and the prefrontal cortex (Seki and Arai 1995; Rapp and Gallagher 1996; Seki 2002; Hedden and Gabrieli 2004; Driscoll and Sutherland 2005; Burke and Barnes 2006; Driscoll et al. 2006). The neuronal networks of the prefrontal cortex (PFC) that mediate executive functions and goal-directed behavior are particularly vulnerable to aging. Recent morphological studies in rats and nonhuman primates have demonstrated that aging impairs the functional integrity of PFC neurons (Morrison and Baxter 2012) associated with agerelated impairments in cognitive performance (Dumitriu et al. 2010; Bloss et al. 2013) and structural plasticity (Bloss et al. 2011). However, the molecular changes that lead to age-related deficits in cognitive PFC-dependent tasks remain largely unknown.

NCAM is an abundant cell adhesion macromolecule that exists in three major isoforms (NCAM-180, NCAM-140, and NCAM120), which differ in molecular weight, distribution, and function (Schuster et al. 2001; Kolkova 2010). NCAM, which plays a key role in neural development, has also been implicated in synaptic

\footnotetext{
${ }^{4}$ These authors contributed equally to this work.

${ }^{5}$ Corresponding author

E-mail: carmen.sandi@epfl.ch

Article is online at http://www.learnmem.org/cgi/doi/10.1101/lm.030064.112.
}

plasticity and cognitive and emotional processes in adulthood (Kiss and Muller 2001; Venero et al. 2006; Maness and Schachner 2007; Conboy et al. 2010; Muller et al. 2010). NCAM mediates activity-dependent synaptic rearrangements through a variety of mechanisms, including the activation of intracellular signaling cascades through fibroblast growth factor receptors (FGFRs) (Buttner and Horstkorte 2010; Ditlevsen and Kolkova 2010), posttranslational modifications involving the attachment of long homopolymers of $\alpha-2,8$-linked sialic acid residues known as polysialic acid (PSA) (Rutishauser 2008) and alterations in NCAM expression at the cell surface (Panicker et al. 2003; Sandi 2004).

In rodents, behavioral manipulations associated with structural and functional alterations in the hippocampus, such as chronic stress, are reportedly accompanied by a reduction of NCAM expression levels, predominately in the hippocampus, but also in other forebrain areas (Sandi et al. 2001; Venero et al. 2002; Alfonso et al. 2006; Sandi and Touyarot 2006; Huang et al. 2008; Bisaz et al. 2011). Thus, NCAM reduction has been proposed to contribute to cognitive disturbances induced by stress (Sandi 2004; Sandi and Bisaz 2007).

There are striking similarities in the structural and functional alterations observed in the rodent hippocampus and PFC in response to chronic stress and aging. Both conditions show similar structural alterations in the hippocampus and the PFC, including atrophy and reduced branching of apical dendrites (Watanabe et al. 1992; Magarinos and McEwen 1995; Radley et al. 2004; 
Cerqueira et al. 2007; Holmes and Wellman 2009), loss of synaptic spines (Sousa et al. 2000; Sandi et al. 2003; Stewart et al. 2005; Radley et al. 2006; Dumitriu et al. 2010; Bloss et al. 2013), and changes in synaptic morphology (Smith et al. 2000; Sousa et al. 2000; Nicholson et al. 2004; Stewart et al. 2005; Donohue et al. 2006; Dumitriu et al. 2010; Bloss et al. 2013). They are both associated with cognitive impairments in hippocampus- and PFC-dependent learning and memory tasks (Barense et al. 2002; McEwen 2002; Ramos et al. 2003; Rosenzweig and Barnes 2003; Sandi 2004; Touyarot et al. 2004; Liston et al. 2006; Conrad 2010; Morrison and Baxter 2012) and with impaired synaptic plasticity (Barnes 1979; Barnes and McNaughton 1980; Pavlides et al. 2002; Alfarez et al. 2003; Dieguez and Barea-Rodriguez 2004; Gerges et al. 2004).

Similar to chronic stress, an isoform-specific reduction of the predominantly neuronal expressed isoform NCAM-180 has been reported in the brain of 2-yr-old rats (Linnemann et al. 1993) and mice (Bahr et al. 1993) and in the hippocampus of early-aged (18-mo-old) rats, which were chronically stressed for $3 \mathrm{wk}$ at the age of 12 mo (Sandi and Touyarot 2006). Interestingly, reduced hippocampal NCAM-180 expression was associated with poor performance in a spatial learning and memory task, indicating a possible link between reduced NCAM expression levels and cognitive impairments associated with aging. Several studies have also reported reduced levels of polysialylated neural cell adhesion molecule (PSA-NCAM) in the aging rodent hippocampus and medial PFC (Fox et al. 1995; Seki and Arai 1995; Abrous et al. 1997; Seki 2002; Varea et al. 2009), further suggesting the potential role of NCAM alterations in the reduced structural and functional plasticity observed in the aging brain. Strikingly, systemic treatment of aged rats with the NCAM-derived peptide FGL (FG-loop, synthetic NCAM mimetic peptide for the activation of FGFRs), which mimics the NCAM interactions with FGFR1 and facilitates AMPA receptor synaptic delivery (Knafo et al. 2012) to improve memory formation (Cambon et al. 2004), exerts neuroprotective effects in a number of aging-associated cellular and molecular alterations (Popov et al. 2008; Ojo et al. 2011, 2012).

Therefore, we hypothesize that altered NCAM expression in the forebrain might be critically involved in age-related impairments in cognitive functions that critically rely on the hippocampus and the PFC. To test this hypothesis, we evaluated working/ episodic-like memory performance in adult (6-9 mo) and aged (17-21 mo) mice with a conditional ablation of the ncam gene in the forebrain (Bukalo et al. 2004). First, we assessed their anxiety-related behaviors and locomotor activity. Next, we tested their performance in two working/episodic-like memory tests (a delayed matching-to-place [DMP] task in the Morris water maze and a delayed reinforced alternation task in the T-maze) that critically rely on the functional integrity of the hippocampus and PFC (Steele and Morris 1999; Chen et al. 2000; Runyan et al. 2005; Yoon et al. 2008). Finally, we measured their NCAM expression levels in the hippocampus and medial PFC. Our results provide evidence that reduced NCAM expression in the forebrain might be a critical factor for aging-induced cognitive disturbances in working/episodic-like memory tasks.

\section{Results}

\section{Anxiety-like behaviors and locomotor activity of adult and aged conditional NCAM-deficient mice}

Due to the emerging evidence showing that anxiety and cognition are closely associated and integrated processes (Beuzen and Belzung 1995; McNaughton 1997; Herrero et al. 2006) we first measured the anxiety-like behaviors and locomotor activity of adult and aged conditional NCAM-deficient mice and their age- matched NCAMff littermates in three different behavioral tests typically used to assess anxiety-like behaviors and locomotor activity in mice: the elevated zero-maze (EZM), the dark/light box (DLB), and the open field (OF).

In the EZM, anxiety-like behaviors were assessed by measuring the percentage of time mice spent and the number of entries they made in the open/unprotected sectors during a 5-min testing period (Fig. 1A,B). A two-way ANOVA for the percentage of time animals spent in open/unprotected sectors revealed a significant effect of the "age" factor $\left(F_{(1,38)}=21.691, P<0.0001\right)$, but a lack of significance in the "genotype" factor $\left(F_{(1,38)}=3.741, P=\right.$ $0.06)$ and the "genotype $\times$ age" interaction $\left(F_{(1,38)}=0.109, P=\right.$
A

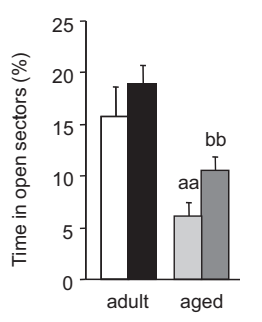

D

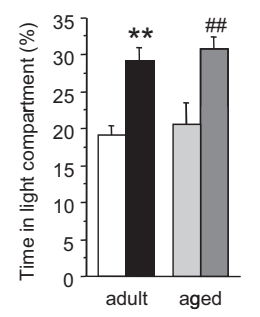

G

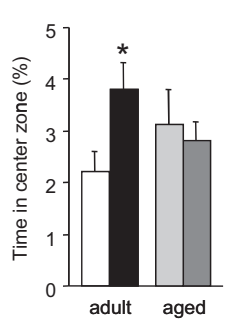

B

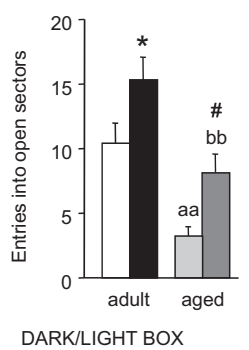

E

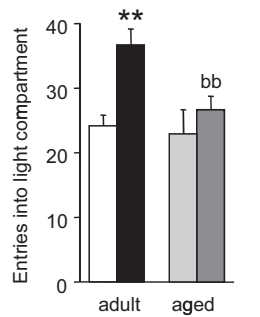

OPEN FIELD

H

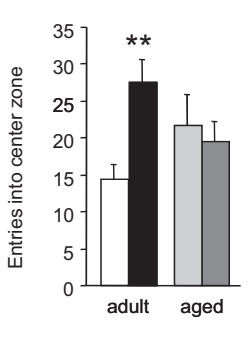

C

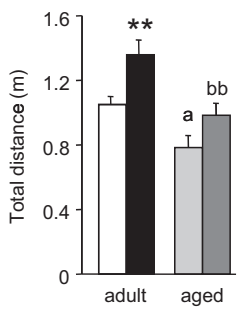

$\mathbf{F}$

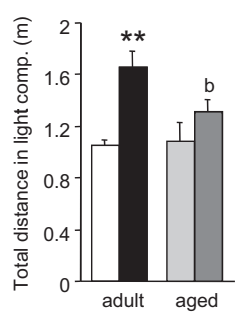

I

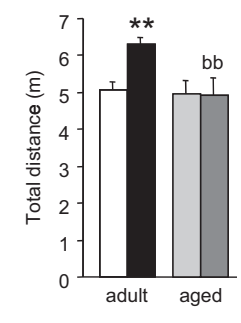

$\square$ Adult, NCAMff

Adult, NCAMffcre

$\square$ Age, NCAMff

$\square$ Aged, NCAMffcre

Figure 1. Behavioral analysis of adult and aged conditional NCAM-deficient male mice (NCAMffcre) and their age-matched NCAMff littermates in the elevated zero-maze (EZM), the dark/light box (DLB), and the open field (OF) tests. Behavioral measurements in the EZM are represented as $(A)$ the percentage of time spent in and $(B)$ number of entries in the open sectors of the EZM, and $(C)$ the total distance traveled in the entire maze. Behavioral measurements in the DLB are represented as $(D)$ the percentage of time spent, $(E)$ number of entries, and $(F)$ the total distance traveled in the light compartment of the DLB. In the open field, behavioral measures are represented as $(G)$ the percentage of time spent in and $(H)$ number of entries in the center zone, and $(I)$ the total distance traveled in the whole arena. The results are the mean \pm SEM ( $N=8-12$ /group; post hoc analysis between genotypes: $\left[{ }^{* *}\right] P<0.01$ and $\left[{ }^{*}\right] P<0.05$ vs. adult NCAMff; $\left[{ }^{\# \#}\right] P<0.01$ and $\left[{ }^{\#}\right]$ $P<0.05$ vs. aged NCAMff; post hoc analysis between age groups: [ $\left.{ }^{\text {aa }}\right]$ $P<0.01$ and $\left[{ }^{\mathrm{a}}\right] P<0.05$ vs. adult NCAMff; $\left[{ }^{\mathrm{bb}}\right] P<0.01$ and $\left[{ }^{\mathrm{b}}\right] P<$ 0.05 vs. adult NCAMffcre). 
0.74). Fisher PLSD post hoc analyses were significant between adult and aged mice of both genotypes (Fig. 1A; NCAMff: $P=$ 0.002 ; NCAMffcre: $P=0.002$ ), but no significance was found between genotypes in either age group (adults: $P=0.25$; aged: $P=$ 0.13). A two-way ANOVA of the number of entries in open/unprotected sectors indicated a significant effect in both the "age" factor $\left(F_{(1,38)}=22.072, P<0.0001\right)$ and the "genotype" factor $\left(F_{(1,38)}=\right.$ $10.153, P=0.029)$, but a lack of significance in the "age $\times$ genotype" interaction $\left(F_{(1,38)}=0.001, P=0.97\right)$. As shown in Figure 1B, Fisher PLSD post hoc analyses were significant between adult and aged mice of both genotypes (NCAMff: $P=0.004$; NCAMffcre: $P=0.0008$ ) and between genotypes at both ages (adults: $P=0.024$; aged: $P=0.037$ ). We also analyzed the total distance the mice traveled in the EZM using two-way ANOVAs, which indicated a significant effect in both the "age" $\left(F_{(1,38)}=\right.$ $16.076, P=0.0003)$ and "genotype" factors $\left(F_{(1,38)}=10.253, P=\right.$ $0.003)$ and a lack of significance in the "age $\times$ genotype" interaction $\left(F_{(1,38)}=0.414, P=0.52\right)$. Fisher PLSD post hoc tests were significant between adult NCAMff and NCAMffcre mice $(P=0.008)$, but not between both genotypes in the aged mice $(P=0.09)$. Post hoc tests were further significant between adult and aged mice of both genotypes (NCAMff: $P=0.03$; NCAMffcre: $P=0.001$ ), indicating a reduction of locomotor activity with aging in animals of both genotypes (Fig. 1C).

In the dark/light box (DLB) test, percentage of time and number of entries in the light compartment were measured during $10 \mathrm{~min}$ and served as an indicator of anxiety-like behaviors (Fig. 1D,E). A two-way ANOVA of the percentage of time animals spent in the light compartment revealed a significant effect in the "genotype" factor $\left(F_{(1,38)}=25.569, P<0.0001\right)$ and no significant effect in either the "age" factor $\left(F_{(1,38)}=0.660, P=0.42\right)$ or the "age $\times$ genotype" interaction $\left(F_{(1,38)}=0.004, P=0.95\right)$. Fisher PLSD post hoc analyses were significant between genotypes at both ages (Fig. 1D; adults: $P=0.0006$; aged: $P=0.001$ ), but not between genotypes in both age groups (NCAMff: $P=0.62$; NCAMffcre: $P=0.51$ ). ANOVA analyses of the number of entries into the light compartment indicated a significant effect of both the "age" $\left(F_{(1,38)}=5.216, P=0.028\right)$ and "genotype" factors $\left(F_{(1,38)}=10.749, P=0.002\right)$, but a lack of significance in the "age $\times$ genotype" interaction $\left(F_{(1,38)}=3.060, P=0.088\right)$. Post hoc analyses were significant between genotypes in adult mice (Fig. 1E; $P=0.0006)$, but not between aged NCAMff and NCAMffcre mice $(P=0.3)$. Post hoc tests were also significant between adult and aged NCAMffcre mice (Fig. 1E; $P=0.004$ ), but not between adult and aged mice of NCAMff (Fig. $1 \mathrm{E} ; P=0.73$ ). For locomotor activity in the DLB, ANOVAs of the total distance traveled in the light compartment revealed a significant effect in the "genotype" factor $\left(F_{(1,38)}=15.378, P=0.0004\right)$, but a lack of significance in the "age" factor $\left(F_{(1,38)}=2.025, P=0.16\right)$ and in the "age $\times$ genotype" interaction $\left(F_{(1,38)}=3.086, P=0.087\right)$ was also found. Post hoc tests were significant between genotypes in adult mice (Fig. 1F; $P=0.0002$ ), but revealed a lack of significance between aged NCAMff and NCAMffcre mice $(P=0.15)$. As shown in Figure 1F, post hoc tests were also significant between adult and aged conditional NCAM-deficient mice $(P=0.02)$, but not between adult and aged NCAMff mice $(P=0.83)$.

In the 10-min OF test, percentage of time spent and number of entries in a virtual square in the middle of the open field box (center zone) were taken as indicators for anxiety-like behaviors, while the total distance animals traveled in the whole OF arena was taken as an indicator of locomotor activity (Fig. 1G-I). ANOVAs of the percentage of time the animals spent in the center zone of the OF indicated no significant effect for the "genotype" factor $\left(F_{(1,38)}=1.665, P=0.2\right)$, the "age" factor $\left(F_{(1,38)}=0.004\right.$, $P=0.95)$, or the "age $\times$ genotype" interaction $\left(F_{(1,38)}=3.829\right.$, $P=0.06)$. Post hoc tests were significant between genotypes in adult animals (Fig. 1G; $P=0.02$ ), but not between genotypes of aged mice $(P=0.65)$ or between adult and aged mice of both genotypes (NCAMff: $P=0.22$; NCAMffcre: $P=0.13$ ). A two-way ANOVA on the number of entries in the center zone revealed a lack of significance in both the "genotype" $\left(F_{(1,38)}=3.215, P=\right.$ $0.81)$ and "age" factors $\left(F_{(1,38)}=0.009, P=0.93\right)$, but a significant effect in the "age $\times$ genotype" interaction $\left(F_{(1,38)}=6.268, P=\right.$ 0.017 ) was found. As shown in Figure $1 \mathrm{H}$, post hoc tests were significant between genotypes in adult animals $(P=0.003)$, but not between genotypes of aged mice $(P=0.63)$ or between adult and aged mice of both genotypes (NCAMff: $P=0.12$; NCAMffcre, $P=$ $0.054)$. The analysis of the total distance traveled in the OF revealed significance in the "age" factor $\left(F_{(1,38)}=4.984, P=\right.$ $0.032)$, but a lack of significance in the "genotype" factor $\left(F_{(1,38)}=3.171, P=0.083\right)$ and the "genotype $\times$ age" interaction $\left(F_{(1,38)}=3.672, P=0.63\right)$. Post hoc tests were significant between genotypes in adult animals (Fig. $1 \mathrm{I} ; P=0.01$ ), but not between genotypes in aged mice $(P=0.93)$. In addition, post hoc tests were also significant between adult and aged NCAMffcre mice (Fig. $1 \mathrm{I} ; P=0.003)$, but not between adult and aged mice of NCAMff $(P=0.84)$.

Altogether, our behavioral analysis revealed that, overall, adult and aged NCAMffcre mice show reduced anxiety-like behaviors compared with those of their age-matched NCAMff littermates and that an increase in anxiety levels accompanies aging in mice of both genotypes. Our results also revealed that, overall, adult NCAMffcre mice display increased locomotor activity compared with that of adult NCAMff littermates and that aging reduces locomotor activity predominantly in NCAM-deficient mice.

\section{Delayed matching-to-place (DMP) task in the Morris water maze}

To assess whether both aged NCAMffcre and aged NCAMff mice have normal visual perception, we first trained all groups of mice during $2 \mathrm{~d}$ using a visible platform paradigm in which the animals learned to find the hidden platform in response to an attached visual cue (i.e., black flag). Repeated measures ANOVAs of the distance the mice swam to find the cued platform revealed no significance in the "genotype" factor $\left(F_{(1,40)}=1.092, P=0.3\right)$, the "age" factor $\left(F_{(1,40)}=1.892, P=0.2\right)$, or the "genotype $\times$ age" interaction $\left(F_{(1,40)}=0.262, P=0.6\right)$, indicating no visual impairments in the aged mice of both genotypes. Repeated measures ANOVAs also indicated significance in the "distance" factor for both ages and genotypes (adult NCAMff: $F_{(3,27)}=15.900, P<$ 0.0001 ; adult NCAMffcre: $F_{(3,33)}=53.076, P<0.0001$; aged NCAMff: $F_{(3,27)}=9.754, P=0.0002$; aged NCAMffcre: $F_{(3,33)}=$ $26.406, P<0.0001$ ), indicating a significant decrease in the average distance the mice required to swim to find the cued platform over trial blocks. However, when the trial blocks were analyzed individually, the ANOVAs revealed a significant effect in the "age" factor observed in the second $\left(F_{(1,40)}=21.240, P<0.0001\right)$ and fourth $\left(F_{(1,40)}=5.838, P=0.02\right)$ trial blocks, and post hoc tests revealed a significantly longer distance for aged mice of both genotypes in the second trial block (NCAMff: $P=0.008$; NCAMffcre: $P=0.0005)$ and a significantly longer distance for aged NCAMff mice in the fourth trial block $(P=0.016)$ to reach the cued platform compared with that of adult mice of the corresponding genotype (Fig. 2A). No significant effect in either the "genotype" factor or the "genotype $\times$ age" interaction was observed in any of the four trial blocks (all $P \geq 0.08$ ). When the average swim speed was analyzed over the four trial blocks during the visual platform paradigm, ANOVAs revealed significance in the "age" factor (Fig. $2 \mathrm{~A} ;\left(F_{(1,40)}=112.435, P<0.0001\right)$, but a lack of significance in the "genotype" factor $\left(F_{(1,40)}=1.444, P=0.24\right)$ and the "genotype $\times$ age" interaction $\left(F_{(1,40)}=1.128, P=0.29\right)$. Fisher 
A

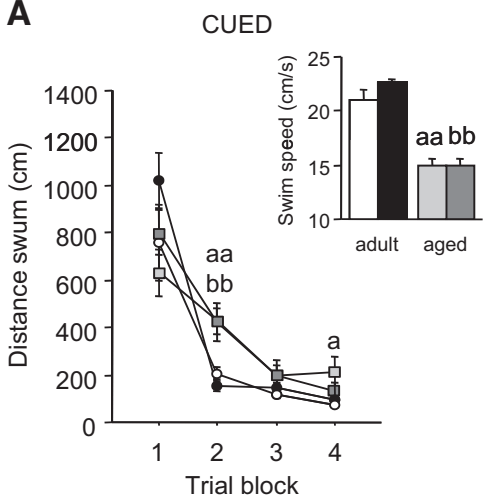

C

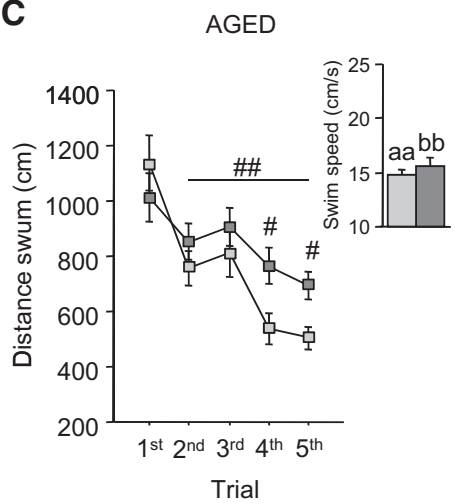

- Adult, NCAMff $\quad$ - Adult, NCAMffcre
B

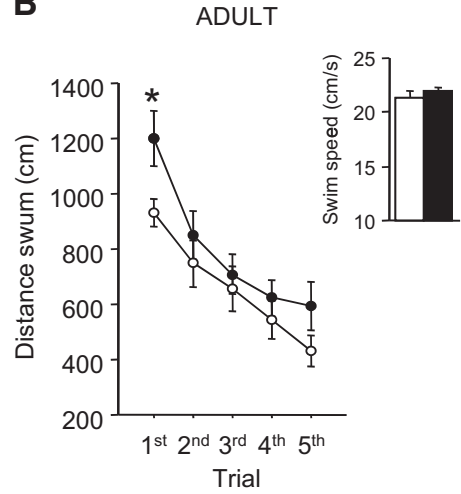

D

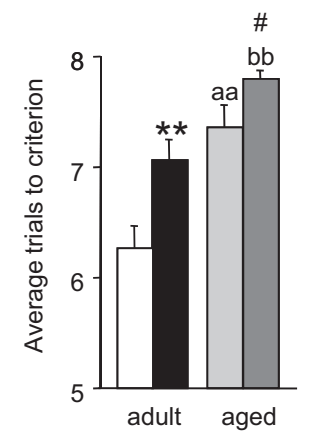

$\square$ Aged, NCAMff

$\square$ Aged, NCAMffcre

Figure 2. Performance of adult and aged conditional NCAM-deficient (NCAMffcre) mice and their NCAMff littermates in the delayed matching-to-place (DMP) task in a Morris water maze. (A) Average distance adult and aged conditional NCAMffcre and NCAMff mice swam to find the submerged cued platform and the average swim speed during the four trial blocks. Average distance the $(B)$ adult and $(C)$ aged mice swam to find the hidden platform during the first five trials of the DMP task (averaged over the six daily training sessions) and the average swim speed across all trials and training sessions. $(D)$ The average number of trials animals required to reach the criterion of three consecutive trials in less than $20 \mathrm{sec}$. The results are the mean \pm SEM ( $N=10-12$ /group; post hoc analysis between genotypes: [**] $P<0.01$ and [*] $P<0.05$ vs. adult NCAMff; $\left[{ }^{\# \#}\right] P<0.01$ and $\left[{ }^{\#}\right] P<0.05$ vs. aged NCAMff; post hoc analysis between age groups: $\left[{ }^{\mathrm{aa}}\right] P<0.01$ and $\left[{ }^{\mathrm{a}}\right] P<0.05$ vs. adult NCAMff; [ $\left.{ }^{\mathrm{bb}}\right] P<0.01$ vs. adult NCAMffcre).

PLSD post hoc tests were significant between adult and aged mice of both genotypes (NCAMff, $P<0.0001$; NCAMffcre, $P<0.0001$ ), indicating a significant lower average swim speed in aged mice compared with that of adult mice of the same genotype (Fig. 2A). Together, these data indicate that the NCAM deficiency in the forebrain of NCAM-deficient mice at both ages does not affect motor activity, vision, or the motivation to escape from the water.

We then assessed working/episodic-like memory in the DMP task in the Morris water maze for the following six consecutive days, as previously described (Steele and Morris 1999; Chen et al. 2000; Zeng et al. 2001). During the DMP task, which requires the dynamic acquisition of ongoing events and measures hippocampus-dependent working/episodic-like memory, mice were trained daily to navigate to a hidden platform at a fixed location in the water maze until reaching a criterion (i.e., three consecutive trials with a latency below $20 \mathrm{sec}$ ), or finishing a maximum number of eight trials. Each mouse performed a minimum of five trials even if a mouse reached the criterion in fewer than five trials. Starting the next day, a new training session began in the same manner except that the platform was moved to a new location
0.84; aged. $\quad$ age groups (adults: $F_{(3,60)}=0.274, P=$ $\left.F_{(3,60)}=0.648, \quad P=0.59\right)$ was also observed Substantial data in the literature indicate that NCAM deficiency manifests as sporadic impairments in individual trials (Bukalo et al. 2004; Bisaz et al. 2011; Bisaz and Sandi 2012); therefore, we also applied unpaired Student's $t$-tests to individual trial blocks. Indeed, significant differences between genotypes were observed in the first trial block in adult mice (Fig. 2B; $t=2.276$, $P=0.034)$, and in the fourth $(t=2.611, P=0.017)$ and fifth $(t=$ $2.784, P=0.012$ ) trial blocks in aged mice (Fig. 2C). No differences in the average swim speed were observed between NCAMffcre and NCAMff mice at both ages (Fig. 2B; adult: $t=1.066, P=0.3$; Fig. $2 \mathrm{C}$; aged: $t=0.843, P=0.41)$. We also analyzed the combined individual trials by repeated measures ANOVAs for adult and aged mice individually. As shown in Supplemental Figure S1, repeated measured ANOVAs for the first trial revealed a significant effect in the "genotype" factor for adult mice $\left(F_{(1,20)}=5.179, P=0.034\right)$. ANOVAs further revealed no significant effect in the "genotype" factor for the first, second, third, fourth, and fifth trials (all $P>$ 0.15 ) for adult mice. However, while repeated measures ANOVAs revealed no significant effect in the "genotype" factor for the 
second and third trials $(P>0.3)$ for aged mice, they indicated a significance difference between genotypes in the fourth $\left(F_{(1,20)}=6.816, P=0.017\right)$ and the fifth $\left(F_{(1,20)}=7.749, \quad P=\right.$ $0.012)$ trials. Importantly, repeated measures ANOVAs also revealed no significance in the "genotype $\times$ trial" interaction in all five trials for both age groups $(P>0.24)$. We also analyzed the "age" effects for NCAMff and NCAMffcre mice individually. For NCAMff mice, repeated measures ANOVAs revealed no significance effect in the "age" factor $\left(F_{(1,18)}=0.789, P=0.39\right)$ or the "age $\times$ trial" interaction $\left(F_{(3,54)}=0.743, P=0.53\right)$. Similarly, for NCAMffcre mice, no significant effects were observed in either the "age" factor $\left(F_{(1,22)}=2.848, P=0.11\right)$ or the "age $\times$ trial" interaction $\left(F_{(3,66)}=0.850, P=0.47\right)$. Moreover, the Student's $t$-test applied to individual trial blocks revealed no significant difference between adult and aged NCAMff (all $P \geq 0.09$ ) and NCAMffcre mice (all $P \geq 0.061$ ). The Student's $t$-test between age groups of the same genotype on the average swim speed over the five compacted trial blocks revealed a significantly lower swim speed for both aged NCAMff $(t=7.395, P<0.0001)$ and aged NCAMffcre mice $(t=7.580, P<0.0001)$ compared with that of adult animals of the same genotype (Fig. 2C).

We also calculated the average number of trials the mice required to reach the criterion (i.e., $<20$ sec escape latency) across all platform locations. Two-way ANOVAs of the number of trials required to reach the criterion indicated a significant effect in both the "age" $\left(F_{(1,40)}=28.851, P<0.0001\right)$ and the "genotype" factors $\left(F_{(1,40)}=12.610, P=0.001\right)$, but a lack of significance in the "age $\times$ genotype" interaction $\left(F_{(1,40)}=1.133, P=0.29\right)$. As shown in Figure 2D, post hoc tests were significant between adult and aged mice of both genotypes (NCAMff: $P<0.0001$; NCAMffcre: $P=0.003$ ) and between genotypes at both ages (adults: $P=0.002$; aged: $P=0.04$ ), indicating a significantly slower acquisition of both adult and aged NCAMffcre mice compared to that of age-matched NCAMff mice.

\section{Delayed reinforced alternation in the T-maze}

One day before training adult and aged NCAMffcre mice and their age-matched NCAMff littermates in the delayed reinforced alternation task in the T-maze, the animals were provided with $10 \mathrm{~min}$ of free exploration to habituate to the handling procedure and testing environment and for the researchers to assess po-
A

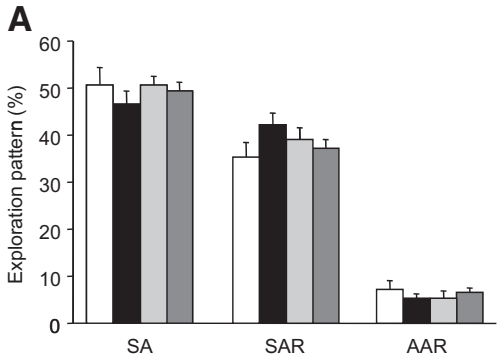

$\square$ Adult, NCAMff
B

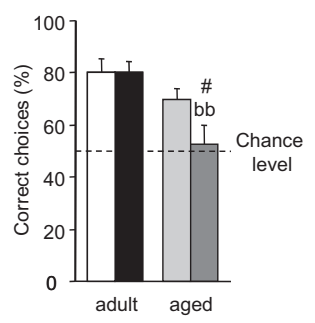

$\square$ Aged, NCAMffcre
Figure 3. The performance of adult and aged conditional NCAM-deficient male mice (NCAMffcre) and their NCAMff littermates in the delayed reinforced alternation task in a T-maze. (A) The exploration patterns of the mice during the 10-min free exploration trial $2 \mathrm{~d}$ prior to testing are represented as the percentage of spontaneous alternation (SA), percentage of same arm returns (SAR), and percentage of alternate arm returns (AAR). (B) Delayed reinforced alternation performance is represented as the percentage of correct choices made during the last five trials of the testing session. The results are the mean \pm SEM $(N=8-10 /$ group; post hoc analysis between genotypes: $[\#] P<0.05$ vs. aged NCAMff; post hoc analysis between age groups: $\left.\left[{ }^{\mathrm{bb}}\right] P<0.01\right)$. tential differences in exploration patterns that could critically interfere with the testing procedure. As shown in Figure 3A, twoway ANOVAs of the percentage of spontaneous alternations (SA) revealed no significance in the "genotype" factor $\left(F_{(1,32)}=\right.$ $0.873, P=0.36)$, the "age" factor $\left(F_{(1,32)}=0.271, P=0.61\right)$, or the "genotype $\times$ age" interaction $\left(F_{(1,32)}=0.295, P=0.59\right)$. Similarly, for the percentage of same arm returns (SAR), ANOVAs indicated no significant effect in the "genotype" $\left(F_{(1,32)}=0.860, P=\right.$ $0.36)$ and "age" $\left(F_{(1,32)}=0.056, P=0.81\right)$ factors or "genotype $\times$ age" interactions $\left(F_{(1,32)}=2.908, P=0.1\right)$. Additionally, ANOVAs of the percentage of alternate arm returns (AAR) revealed no significance in the "genotype" factor $\left(F_{(1,32)}=0.061, P=0.81\right)$, the "age" factor $\left(F_{(1,32)}=0.44, P=0.83\right)$, or in their interaction $\left(F_{(1,32)}=0.980, P=0.33\right)$, indicating no difference in exploration patterns between "age" and "genotype" groups (Fig. 3A). On the subsequent day, the animals were subjected to training in which they were allowed to make four forced choices. To exclude potential differences in motivational guided behaviors or lethargic behaviors of aged mice, we also analyzed the average latency required for each mouse to enter the open choice arms during training (adult NCAMff: $24.0 \pm 6.9 \mathrm{sec}$; adult NCAMffcre: $17.0 \pm$ $3.8 \mathrm{sec}$; aged NCAMff: $15.7 \pm 4.6 \mathrm{sec}$; aged NCAMffcre: $8.4 \pm 1.1$ sec; data not shown). Two-way ANOVAs on the latency required to enter the open arm revealed no significance in the "age" factor $\left(F_{(1,32)}=3.007, P=0.09\right)$, the "genotype" factor $\left(F_{(1,32)}=2.166\right.$, $P=0.15)$, or the "age $\times$ genotype" interaction $\left(F_{(1,32)}=0.001\right.$, $P=0.98)$.

On the third day, all animals were tested for their delayed reinforced alternation performance in the T-maze, a working memory task that critically depends on both the hippocampus and the mPFC (Lalonde 2002; Runyan et al. 2005; Yoon et al. 2008). In this task, the animal had to choose between entering one of two arms in which a food reinforcer was present in the end of one arm. The location of the reinforcer shifted to the alternate arm after a successful retrieval of the food. In order to perform efficiently in this task, the animals had to alternate choices on successive trials (win-shift) in order to minimize the amount of effort required to locate the food (Kolata et al. 2007, 2008). ANOVAs on the percentage of correct choices revealed a significant effect in the "age" factor $\left(F_{(1,32)}=12.579, P=0.001\right)$, but not in the "genotype" factor $\left(F_{(1,32)}=2.739, P=0.11\right)$ or the "genotype $\times$ age" interaction $\left(F_{(1,32)}=2.379, P=0.11\right)$. Post hoc analyses further revealed a significant difference between adult and aged NCAMffcre mice (Fig. 3B; $P=0.0009)$ and between aged NCAMffcre and NCAMff mice $(P=0.033)$. No significance was observed between the genotypes in adult mice $(P=0.99)$ or between adult and aged NCAMff mice (Fig. 3B; $P=0.19$ ). Additionally, while the adult animals of both genotypes and the aged NCAMff mice performed significantly above chance levels of 50\% correct choices (Univariant ANOVA; adult NCAMff: $P<0.0001$; adult NCAMffcre: $P=0.0003$; aged NCAMff: $P=0.0011)$, the aged NCAMffcre mice performed at chance levels $(P=0.75)$. We also analyzed the average latency required to enter the choice arms across the six test trials (adult NCAMff: $12.7 \pm 1.7 \mathrm{sec}$; adult NCAMffcre: $9.4 \pm 2.1 \mathrm{sec}$; aged NCAMff: $13.1 \pm 2.6 \mathrm{sec}$; aged NCAMffcre: $7.6 \pm 0.7 \mathrm{sec}$; data not shown). Two-way ANOVAs of the latency to enter the choice arms revealed a significant effect in the "genotype" factor $\left(F_{(1,32)}\right.$ $=5.267, P=0.03)$, but no significance was observed in the "age" factor $\left(F_{(1,32)}=0.134, P=0.72\right)$ or the "genotype $\times$ age" interaction $\left(F_{(1,32)}=0.309, P=0.58\right)$. Post hoc analyses, however, revealed no significant differences between the age and genotype groups (all $P>0.2$ ). Taken together, the data of the delayed reinforced alternation test indicate that aging in animals with reduced NCAM expression in the forebrain is associated with pronounced working memory deficits in this task compared with those of wildtype animals. 
A

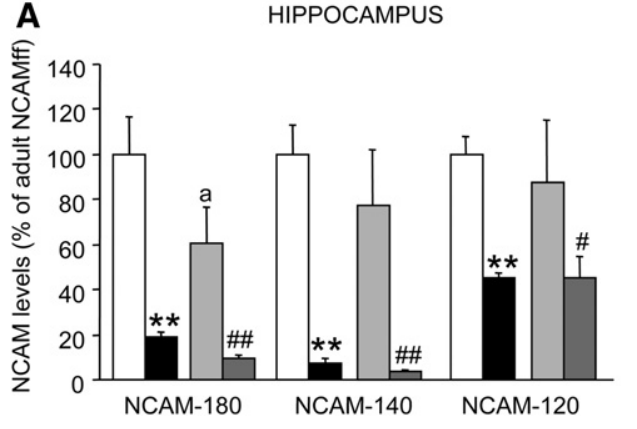

B

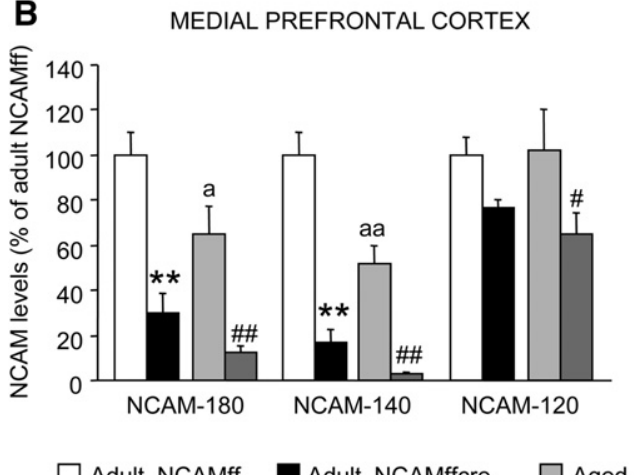

Aged, NCAMff
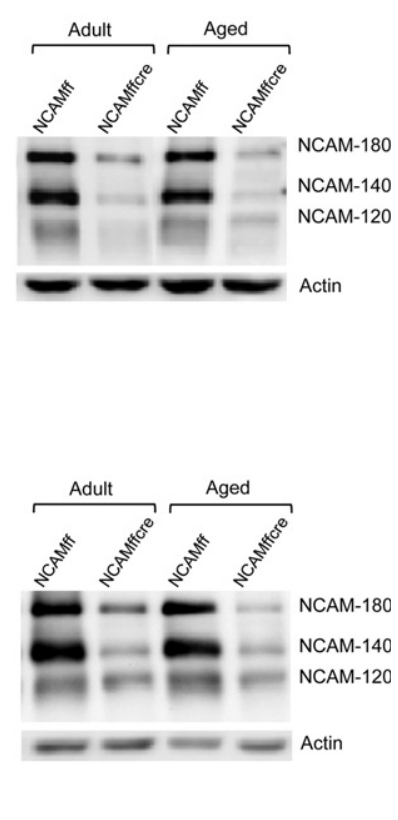

Aged, NCAMffcre

Figure 4. NCAM expression levels in the hippocampus $(A)$ and medial prefrontal cortex $(B)$ of naive adult and aged conditional NCAM-deficient mice (NCAMffcre) and their NCAMff littermates. The NCAM expression levels are represented as a percentage of adult NCAMff expression levels. The results are the mean \pm SEM $\left(N=5-8\right.$ /group; post hoc analysis between genotypes: $\left[{ }^{* *}\right] P<0.01$ vs. adult NCAMff; $\left[{ }^{\# \#}\right] P<0.01$ and $\left[{ }^{\#}\right] P<0.05$ vs. aged NCAMff; post hoc analysis between age groups: $\left[{ }^{\text {aa }}\right] P<0.01$ and $\left[{ }^{a}\right] P<0.05$ vs. adult NCAMff).

\section{NCAM expression in the hippocampus and medial prefrontal cortex (mPFC)}

Hippocampal and mPFC NCAM levels were evaluated in crude synaptosomal preparations from adult and aged NCAMffcre mice and their age-matched NCAMff littermates. The expression of NCAM was expressed as a percentage of that of adult NCAMff animals (Fig. 4A,B). Considering the three major NCAM isoforms together, repeated measures ANOVAs for the three major NCAM isoforms in the hippocampus revealed a significant effect in the "genotype" factor $\left(F_{(1,24)}=41.630, P<0.0001\right)$, but a lack of significance in the "age" factor $\left(F_{(1,24)}=2.049, P=0.16\right)$ and "age $\times$ genotype" interaction $\left(F_{(1,24)}=1.012, P=0.32\right)$. Additionally, repeated measures ANOVAs also indicated a significant effect in the "isoform" factor $\left(F_{(2,48)}=14.544, P<0.0001\right)$ and the "isoform $\times$ genotype" interaction $\left(F_{(2,48)}=6.675, \quad P=0.003\right)$, but no significant effect for the other paired interaction between these factors. When individual isoforms in hippocampal fractions were analyzed separately using two-way ANOVAs, a significant effect in the "genotype" factor of all three isoforms (NCAM-180: $F_{(1,24)}=34.824, \quad P<0.0001 ;$ NCAM-140: $F_{(1,24)}=51.259, \quad P<$ 0.0001; NCAM-120: $\left.F_{(1,24)}=16.456, P=0.0005\right)$ was observed. Additionally, ANOVAs of the individual NCAM isoforms revealed a significant effect in the "age" factor for the NCAM-180 isoform $\left(F_{(1,24)}=4.763, P=0.04\right)$; however, a lack of significance in this factor was observed for the expression of the NCAM-140 $\left.F_{(1,24)}=1.289, P=0.27\right)$ and NCAM-120 $\left(F_{(1,24)}=0.269, P=\right.$ $0.61)$ isoforms. No significance was observed in the "age $\times$ genotype" interaction for all three isoforms (NCAM-180: $F_{(1,24)}=$ $1.732, P=0.39$; NCAM-140: $F_{(1,24)}=0.659, P=0.42$; NCAM-
120: $\left.F_{(1,24)}=0.309, \quad P=0.58\right)$. Subsequently, we performed Fisher PLDS post hoc analyses for each major NCAM isoform and observed significantly lower NCAM expression levels of both adult and aged NCAMffcre mice compared with those of their age-matched NCAMff littermates (Fig. 4A; for all $P \leq$ $0.03)$. Post hoc analyses between age groups within each genotype individually revealed a significantly lower expression of the NCAM-180 isoform in aged NCAMff mice (Fig. 4A; $P=0.027$ ) compared with that in adult mice of the same genotype, while no significance was observed in either the NCAM-140 or the NCAM-120 isoform (both $P>$ 0.2 ). Moreover, post hoc analyses between adult and aged NCAMffcre mice revealed no significance in any of the three major NCAM isoforms (all $P \geq$ $0.53)$.

For NCAM expression levels in mPFC fractions, repeated measures ANOVAs for all three major isoforms revealed a significant effect in the "genotype" $\left(F_{(1,24)}=\right.$ 42.452, $P<0.0001)$ and "age" factors $\left(F_{(1,24)}=6.706, P=0.016\right)$, while no significance was observed for the "genotype $\times$ age" interaction $\left(F_{(1,24)}=0.665\right.$, $P=0.42$ ). Additionally, repeated measures ANOVAs also revealed significance in the "isoform" factor $\left(F_{(2,24)}=\right.$ $101.174, P<0.0001)$, the "isoform $\times$ genotype" $\left(F_{(2,24)}=18.380, \quad P<0.0001\right)$, the "isoform $\times$ age" $\left(F_{(2,24)}=9.925, P=\right.$ $0.0002)$, and the "isoform $\times$ genotype $\times$ age" $\left(F_{(2,48)}=7.117\right.$, $P=0.002)$ interactions. Similarly to hippocampal fractions, significant effects in the "genotype" factor were observed for all three major NCAM isoforms (two-way ANOVA; NCAM-180: $F_{(1,24)}=44.305, \quad P<0.0001 ; \quad$ NCAM-140: $F_{(1,24)}=77.607, \quad P<$ 0.0001 ; NCAM-120: $\left.F_{(1,24)}=9.624, P=0.005\right)$. In addition, significance in the "age" factor was observed for the NCAM-180 $\left(F_{(1,24)}=8.433, P=0.008\right)$ and the NCAM-140 $\left(F_{(1,24)}=17.419\right.$, $P=0.0003)$, but not for the NCAM-120 isoform $\left(F_{(1,24)}=0.223\right.$, $P=0.64)$. ANOVAs also revealed a significant "genotype $\times$ age" interaction for expression levels of the NCAM-140 isoform $\left(F_{(1,24)}=5.347, P=0.03\right)$, but not for the NCAM-180 $\left(F_{(1,24)}=\right.$ $0.93, P=0.34)$ and the NCAM-120 isoforms $\left(F_{(1,24)}=0.443, P=\right.$ $0.51)$. Fisher PLSD post hoc analyses for each major NCAM isoform revealed significantly lower expression levels for the NCAM-180 and NCAM-140 isoforms $(P<0.0001)$ in adult NCAMffcre mice and all three isoforms in aged NCAMffcre mice (all $P \leq 0.02$ ) compared with those of their age-matched NCAMff littermates (Fig. 4B). Additionally, post hoc analyses revealed significance between adult and aged NCAMff mice for the NCAM-180 (Fig. 4B; $P=0.015$ ) and the NCAM-140 (Fig. 4B; $P=0.0002$ ) isoforms, with lower expression levels of these isoforms in aged NCAMff mice. No differences between adult and aged NCAMff mice were observed for the expression levels of the NCAM-120 isoform $(P=0.9)$ as well as the expression level of all isoforms between adult and aged NCAMffcre mice (all $P \geq 0.16$ ). Taken together, these data indicate that aging in wild-type mice is associated with an isoform-specific reduction of NCAM expression levels in the hippocampus and the $\mathrm{mPFC}$. 


\section{Discussion}

Cognitive processes mediated through the hippocampus (declarative memory) and the prefrontal cortex (working/episodic-like memory) are the most vulnerable to aging (Barense et al. 2002; Erickson and Barnes 2003; Ramos et al. 2003; Hedden and Gabrieli 2004; Driscoll and Sutherland 2005; Driscoll et al. 2006; Morrison and Baxter 2012). Substantial evidence indicates that age-related cognitive decline is more likely associated with alterations in synaptic connectivity than with neuronal loss (Peters et al. 2008; Morrison and Baxter 2012). However, the molecular changes that underlie the vulnerability to cognitive impairments associated with aging are poorly understood. In this study, using conditional NCAM-deficient mice (NCAMffcre) in which the ncam gene is ablated in glutamatergic neurons of the forebrain, we addressed whether NCAM deficiency alters vulnerability for age-related cognitive decline in working/episodic-like memory tasks.

Our results indicate that aging in conditional NCAM-deficient (NCAMffcre) mice is associated with impairments in two types of working/episodic-like memory tasks, which critically depend on the functional integrity of the PFC and the hippocampus (i.e., a delayed matching-to-place and a delayed reinforced alternation tasks [Steele and Morris 1999; Chen et al. 2000; Runyan et al. 2005; Yoon et al. 2008; Zhang et al. 2008]). We also find that aging in wild-type (NCAMff) mice leads to an isoform-specific reduction of NCAM-180 expression levels in the hippocampus and the PFC and a further reduction in NCAM-140 in the PFC. However, aging does not alter the already reduced NCAM expression displayed by NCAMffcre mice.

The reported cognitive deficits cannot be attributed to increased anxiety-like behaviors or reduced locomotor activity. While aging in both genotypes was associated with an increase in anxiety-like behaviors, both adult and aged NCAMffcre mice displayed lower anxiety-like behaviors than age-matched NCAMff littermates. We have previously reported reduced anxiety-like behaviors in adult conditional NCAM-deficient mice (Bisaz and Sandi 2010; Bisaz et al. 2011); in this study, we show in addition that this behavioral characteristic in conditional NCAM-deficient mice is also manifested during aging. We also observed generally increased locomotor activity in adult NCAMffcre mice compared with that in adult NCAMff mice, but no difference was observed between genotypes in aged animals.

In the spatial delayed matching-to-place tests in the Morris water maze, aged NCAM-deficient (NCAMffcre) mice swam longer distances to find the hidden platform and required a higher number of trials to reach the training criterion than their age-matched NCAMff littermates (adult NCAMffcre mice only showed deficits as compared to their wild-type littermates in this latter parameter). These deficits seem to be specific to the cognitive domain. Although aged mice of both genotypes were impaired in getting access to the cued platform on the second trial block, and aged NCAMffcre as well in the fourth, as compared with adult animals of the corresponding genotype, all aged mice performed as adult mice in the third trial block suggesting that the observed difference most likely reflects attentional deficits in aged rodents rather than general visual or locomotor impairments (Rowe et al. 1998; van der Staay 2002). Importantly, no differences were observed between genotypes in swim speed.

Age-related working memory impairments of NCAMffcre mice were also observed in the delayed reinforced alternation task in the T-maze, in which the animals maintained the location of the previous visited arm of the T-maze online during the 20-sec intertrial interval to make a correct choice in the following trial. While the adult mice of both genotypes and aged NCAMff littermates performed significantly above chance level and made more correct than incorrect choices, the aged NCAMffcre mice only performed at the chance level. Importantly, differences in exploration patterns in the T-maze cannot account for the poor performance of the aged NCAMffcre mice in this test, as the mice of both genotypes and age groups displayed a comparable percentage of spontaneous alternations, same arm returns, and alternate arm returns. Similarly, no differences were found in the latency animals needed to enter the choice arms during the four forcedtraining trials or the six testing trials, indicating no general movement disorders, lethargic behaviors, or motivational deficits to obtain the food reward.

We also report that adult conditional NCAM-deficient mice did not exhibit impairments in the spatial working/episodiclike memory task, which seems at odds with previous reports of mild deficits in spatial reference memory, manifested as sporadic impairments on individual trials and of profound impairments in reversal learning given after training in a spatial reference memory task (Bisaz et al. 2011; Bisaz and Sandi 2012). The lack of difference in performance between the two adult genotypes in the delayed matching-to-place task fits with early reports indicating that the NCAMffcre mice perform well during the initial stages of learning but were impaired in the fine-tuning of spatial searching that manifests with increasing training (Bukalo et al. 2004). On the other hand, the higher average number of trials that the adult NCAMffcre mice required to reach the training criterion might suggest a slower acquisition rate and/or less precise spatial searching of these mice than those of their control littermates.

To our knowledge, this is the first study showing that reduced NCAM expression in the forebrain is associated with higher vulnerability to develop cognitive impairments in working/episodic-like memory tasks with aging. Indirect evidence for altered NCAM expression and the occurrence of cognitive decline with aging have also been reported in both clinical and experimental research studies. For example, increased concentrations of proteolytic fragments of NCAM have been observed in the cerebrospinal fluid (CSF) of patients suffering from dementia and neurodegenerative diseases, increasing with age and being correlated with the neurodegenerative etiology (Strekalova et al. 2006).

Aging shows different effects in the hippocampus and PFC. Synaptic aging and cognitive impairments in the PFC are primarily associated with an extensive loss of thin highly plastic and dynamic dendritic spines, which might be particularly important for the temporal coding of information. However, large, complex synapses in the hippocampus, which are important for the induction and maintenance of long-term potentiation (LTP), appear to be the most vulnerable to aging (Morrison and Baxter 2012). Interestingly, the neuron-specific expression of the NCAM-180 isoform is specifically enriched in the postsynaptic density and potentially plays an important role in the stabilization of mature, complex synapses (Polo-Parada et al. 2004; Walmod et al. 2004). It is tempting to speculate that the reduction in NCAM-180 observed in the hippocampus might be associated with reductions in the number and length of perforated synapses in the CA1 region and the dentate gyrus described in aged rats (Smith et al. 2000; Nicholson et al. 2004). Consistent with this hypothesis, isoform-specific NCAM-180 knockout mice exhibit a dispersed pyramidal cell layer in the CA3 region.

We also observed a pronounced reduction of the NCAM-140 isoform in the PFC of aged wild-type mice. A reduction in the expression levels of the NCAM-140 isoform have also been reported in the hippocampus of rats chronically stressed for $3 \mathrm{wk}$, a condition that is accompanied by a loss of excitatory glutamatergic synapses and a reduction in the surface area of postsynaptic densities (Sousa et al. 2000; Sandi et al. 2003; Stewart et al. 2005). 
Similar morphological alterations were recently reported to occur with aging in the PFC (Bloss et al. 2013), suggesting the potential involvement of reduced NCAM expression in the morphological alterations that occur with aging in the PFC.

Whereas constitutive NCAM knockout mice have been much characterized (Theodosis et al. 2004; Tereshchenko et al. 2011; Kochlamazashvili et al. 2012), information regarding the (neuro)physiological impact of the mutation in NCAMffcre mice is scarce. However, available information indicates an existing vulnerability in these mice. In nonaged adult mice, long-term potentiation (LTP) in the CA1, but not CA3, region of the hippocampus was found to be reduced in NCAMffcre mice, in agreement with their normal mossy fiber lamination (Bukalo et al. 2004). Moreover, these mice display an enhanced vulnerability to develop deficits in hippocampus-dependent (note that functional changes in PFC-dependent tasks were not evaluated) learning tasks when exposed to stress (Bisaz and Sandi 2012). Our study extends the implications of reduced forebrain NCAM expression to functional deficits in both hippocampus- and PFC-dependent functions with aging. Further studies should be addressed to understand the mechanisms involved at cellular and network levels.

In conclusion, the results of this study indicate that decreased NCAM expression in the forebrain critically enhances the vulnerability to develop aging-induced cognitive disturbances in learning and memory tasks that critically rely on the functional integrity of the PFC and the hippocampus. NCAM deficits in the forebrain might result in a reduced capacity for structural plasticity in relevant neuronal networks, which are necessary to mediate working/episodic-like memory processes. In addition, the aginginduced reduction of NCAM expression levels in the MPFC might be critically involved in the structural alterations in aged rodents and nonhuman primates. Although further work is needed to elucidate the precise role of NCAM in age-related cognitive impairments, intervention studies using systemic and/or regionspecific treatments with NCAM mimetic peptides should be conducted to further verify this conclusion.

\section{Materials and Methods}

\section{Subjects}

Experiments were conducted on adult (6-9 mo old) and aged (17-21 mo old) in-house bred conditional NCAM-deficient male mice (NCAMffcre) and their age-matched wild-type male littermates (NCAMff). The generation of conditional NCAM-deficient mice has been previously described (Bukalo et al. 2004). Briefly, homozygous ncam-floxed female mice were bred with homozygous ncam-floxed male mice expressing the cre-recombinase under the control of the promoter of the $\alpha$-subunit of the caciumcalmodulin-dependent protein kinase II ( $\alpha$ CaMKII). The progeny were homozygous for the ncam-floxed alleles; half of these mice carried the $\alpha$ CaMKII-cre transgene (NCAMffcre), and the rest were wild-type littermates (NCAMff). All mice were backcrossed for more than 10 generations into the $\mathrm{C} 57 \mathrm{BL} / 6 \mathrm{~J}$ background and were housed in groups of 2-6 in standard plastic cages on a 12-h light/dark cycle (lights on at 07.30). The temperature in the animal housing room was maintained at $21 \pm 1^{\circ} \mathrm{C}$. Throughout the experimental period, the mice were provided ad libitum access to water and food, except during the T-maze experimental period, when the mice were subjected to a food restriction schedule to maintain a body weight of $\sim 90 \%$ of the freely fed weight (adult NCAMff: $37.4 \pm 1.5 \mathrm{~g}$; adult NCAMffcre: $32.5 \pm 0.8 \mathrm{~g}$; aged NCAMff: $38.1 \pm 2.5 \mathrm{~g}$; aged NCAMffcre: $36.6 \pm 1.6 \mathrm{~g})$. All animal experiments were performed in accordance with the Swiss National Institutional Guidelines on Animal Experimentation, and the Swiss Cantonal Committee for Animal Experimentation approved all experimental procedures. The number of mice used in this study and the animal suffering in all procedures was maintained at a minimum.

\section{Elevated zero-maze}

In the elevated zero-maze (EZM), a white plastic elevated $(46 \mathrm{~cm}$ above the ground) annular runway (5.5-cm wide, 46-cm outer diameter, and $35-\mathrm{cm}$ inner diameter) was used for testing mice anxiety levels, as previously described (Bisaz et al. 2011). Two opposing $90^{\circ}$ sectors of the runway were protected with $13.5-\mathrm{cm}$ high inner and outer walls, and the three zones were defined as follows: an intermediate zone comprising four $30^{\circ}$ segments at the ends of the protection walls separated by the two $50^{\circ}$-wide closed/protected and two $70^{\circ}$-wide open/unprotected exploration zones. The mice were observed for $5 \mathrm{~min}$ in the EZM under dim and dispersed light conditions, and the trajectories of each mouse were automatically recorded using video tracking (EthoVision 3.0, Noldus). The entries into the open sectors were detected only when the animal entered with all four paws. Under this criterion, the percentage of time and number of entries into the open sectors and the total distance the animals traveled during the entire testing period were analyzed. The total distance traveled served as an indicator of spontaneous locomotor activity, while differences in frequency and time spent in the open sectors were considered to be indicators of anxiety-related behaviors. Between experimental sessions, the maze was cleaned with $5 \%$ ethanol/water.

\section{Dark/light box}

Anxiety-like behaviors were also evaluated in a light/dark box (DLB), as previously described (Bisaz and Sandi 2010). A $27 \times$ $27 \times 26-\mathrm{cm}$ lit (room light 45-50 lx) white compartment with open top was connected through an opening entrance $(5 \times 5$ $\mathrm{cm})$ to a $27 \times 27 \times 26$-cm black box compartment covered with a lid. Each subject was placed in the center of the dark compartment and total distance traveled, frequency of entries, and percent time in the light compartment were recorded using video tracking for $10 \mathrm{~min}$ (EthoVision 3.0, Noldus). Differences in the number of entries and the time spent in the light compartment were considered as indicators of anxiety-related behaviors. Between sessions, both compartments were cleaned with 5\% ethanol/water.

\section{Open field}

The behavior of the mice was also assessed in the open field (OF) test as previously described (Jakobsson et al. 2008; Bisaz and Sandi 2010). Briefly, the mice were placed in the center of a white quadratic box $(50 \times 50 \times 37 \mathrm{~cm})$ and allowed to move freely for 10 min under dim and dispersed light conditions while their trajectories were recorded using a video tracking system (EthoVision 3.0, Noldus). The total number of entries and time spent in the center zone $(25 \times 25-\mathrm{cm}$ virtual square in the middle of the $\mathrm{OF})$ were interpreted as anxiety-like behaviors, whereas the total distance was used as an index of locomotor activity.

\section{Delayed matching-to-place (DMP) task in a Morris water maze}

The DMP task took place in a white circular water maze $(140-\mathrm{cm}$ diameter) filled with opaque-colored water $\left(26 \pm 1^{\circ} \mathrm{C}\right)$ and a hidden platform $(10 \times 10 \mathrm{~cm})$ submerged $\sim 1.3 \mathrm{~cm}$ under the water surface, as previously described (Bisaz et al. 2011; Bisaz and Sandi 2012). The DMP task was conducted as previously described (Chen et al. 2000; Zhang et al. 2008), with minor modifications. Adult and aged NCAMffcre mice and their NCAMff littermates were first pretrained using a visible platform paradigm (four trials per day for two consecutive days with an intertrial interval [ITI] of $\sim 30 \mathrm{~min}$ ). On the third day, the mice were trained to find a hidden platform with a fixed location until they reached the criterion of three consecutive trials with an average escape latency of less than $20 \mathrm{sec}$ or until a maximum of eight trials were completed (ITI $\sim 30 \mathrm{~min}$ ). If a mouse reached the criterion in fewer than five trials, it was continuously trained to complete five trials to obtain a complete set of data for all mice for the first five trials. The next day, the mice were trained to a new hidden platform location 
in the same manner as that used for the first location. This protocol was repeated four more times until a total of six platform locations were learned. The data were collected using a video camera fixed to the ceiling connected to a video tracking system (EthoVision 3.0, Noldus). For the analysis, individual trials from the six training days were collapsed into first, second, third, fourth, and fifth trials, as previously described (Zeng et al. 2001; Zhang et al. 2008). To minimize the possible confounds caused by motivational, motor, and sensory effects, the performance in the visual platform and the DMP were analyzed in terms of the swimming distance required to find the hidden platform.

\section{Delayed reinforced alternation}

In this task, the animals had to choose between one of two arms of a T-maze, which consisted of a start arm $(10-\mathrm{cm}$ wide $\times 70-\mathrm{cm}$ long) and two choice arms (10-cm wide $\times 33$-cm long). The entire maze was enclosed in 12-cm-high walls. The initial segment of the start arm was segregated using a guillotine door, which defined the start box. At the entry of each choice arm, there was another experimenter-operated door. A food container (2-cm diameter $x$ $1.5-\mathrm{cm}$ high) was located at the end of each choice arm. One day before training, the animals were allowed $10 \mathrm{~min}$ of free exploration with all doors open and none of the choice arms baited. This trial was later analyzed for differences in exploration pattern, including the percentage of spontaneous alternations (SA), same arm returns (SAR), and alternate arm returns (AAR). The percentage of spontaneous alternations was defined as a ratio of the arm choices that differed from the previous two choices to the total of possible choices during the run (i.e., total arm entries minus two), as previously described (Wietrzych et al. 2005; Yamada et al. 2005). The alternate arm returns and same arm returns were also scored for each animal to assess differences in exploration patterns. The training in delayed reinforced alternation task proceeded as previously described (Kolata et al. 2007, 2008).

Briefly, one day after their 10-min habituation to the T-maze, the animals were acclimated to the training conditions and allowed to make four forced choices. For the first exposure, the animal was held in the start box for $30 \mathrm{sec}$, after which the mouse was allowed to traverse the maze; the door of the right choice arm was closed, whereas the left door was open. A 50- $\mu \mathrm{L}$ drop of $50 \%$ condensed milk in water was located in the food container and served as the reinforcer. Upon entry into the left (open) choice arm, the guillotine door at the entrance was lowered and the animal was allowed to consume the food, after which the mouse was returned to the start box for a 20 -sec intertrial interval (ITI). For the second exposure, this procedure was repeated but the right arm was open and the left arm was closed. After a 20-sec ITI, this sequence was repeated for two additional exposures. The average latency of the animals to enter the choice arm was analyzed and served as an indicator of motivational behaviors. On the subsequent day, the animals were tested for delayed reinforced alternation performance. Briefly, in the first trial, a reinforcer was available in both food containers and the animal could make a free choice. In the second trial, a reinforcer was available only in the arm not entered in the first trial. If the animal chose the correct arm, it was allowed to consume the food reinforcer and the location of the reinforcer alternated on the following trial. If an incorrect choice was made, the animal was kept in the choice arm for $60 \mathrm{sec}$. In either case, after the reinforcer was consumed or after $60 \mathrm{sec}$, the animal was placed back in the start box to begin a 20-sec ITI. Animals' correct/incorrect choices were recorded on each of the five trials. If an animal did not consume the food reinforcer inside the choice arm within $300 \mathrm{sec}$, it was placed back into its home cage and excluded from further testing and analysis (two adult NCAMffcre and four aged NCAMffcre).

\section{Tissue preparation and Western blot analysis}

The expression levels of the three main NCAM isoforms (NCAM-180, NCAM-140, and NCAM-120) were measured in Western blots of crude synaptosomal preparations of freshly dissected whole hippocampal and mPFC (including the infralimbic and prelimbic cortex) fractions of naive adult ( $N=8$ /group) and aged ( $N=5-7 /$ group) NCAMffcre and NCAMff mice, as previously described (Conboy and Sandi 2010; Bisaz et al. 2011; Bisaz and Sandi 2012). Briefly, synaptosomes from each mouse were incubated overnight at room temperature with endoneuraminidase- $\mathrm{N}$ (AbCys, final dilution 1:120) to selectively cleave the polysialic acid moiety of NCAM. The samples were boiled at $100^{\circ} \mathrm{C}$ for 5 min in $70 \mathrm{mM}$ Tris- $\mathrm{HCl}$ (pH 6.8), $33 \mathrm{mM} \mathrm{NaCl}, 1 \mathrm{mM}$ ethylenediaminetetraacetic acid, 2\% sodium dodecyl sulfate (SDS), $0.01 \%$ bromophenol blue, $10 \%$ glycerol, and 3\% dithiothreitol. Approximately $5 \mathrm{mg}$ of total protein from each sample was separated using 7.5\% SDS-polyacrylamide gel electrophoresis and transferred to a nitrocellulose membrane (Protran, Whatman $\mathrm{GmbH}$ ). After saturation of the nonspecific sites with $5 \%$ nonfat dry milk in $10-\mathrm{mM}$ Tris- $\mathrm{HCl}$ ( $\mathrm{pH} 7.4$ ) containing $150-\mathrm{mM} \mathrm{NaCl}$ and $0.05 \%$ Tween-20 (TBST), the membranes were probed overnight at $4^{\circ} \mathrm{C}$ with primary antibodies against NCAM (1:5000, Millipore) or actin (1:20,000, Sigma), washed with TBST, incubated for $2 \mathrm{~h}$ with the appropriate secondary horseradish peroxidase-linked antibodies (NCAM, 1:1000 goat anti-rabbit IgG, Molecular Probes; actin, 1:10,000 goat anti-mouse IgG, Calbiochem), and finally developed using the SuperSignal West Dura Substrate (Pierce). The bands were detected using the ChemiDoc XRS system (Bio-Rad), and the densitometric analysis of the bands was calculated using NIH ImageJ $1.44 \mathrm{p}$ software (http://imagej.nih.gov). Following normalization to within-lane actin, the expression of all three main NCAM isoforms was expressed as the percentage of the adult NCAMff mice. The linear range of the specific antibody signal detection was determined at the outset of these experiments, and all experimental samples were loaded at a concentration within the linear range of the antibody signal detection.

\section{Statistical analysis}

All results are expressed as the mean \pm standard error of the mean (SEM) analyzed using StatView software version 5.0 (SAS Institute). The data were analyzed using analysis of variance (ANOVA) with or without repeated measures, as appropriate. Post hoc tests (Fisher's protected least significant difference [PLSD]) were applied whenever ANOVAs yielded significance. The significance of the results was accepted at $P<0.05$.

\section{Acknowledgments}

The authors thank Prof. Melitta Schachner for the initial donation of conditional NCAM-deficient mice breeding pairs and Coralie Siegmund for help with NCAM Western blots. This work was supported through grants from the EU (FP7-HEALTH-F2M-2008201600, MemStick), the Swiss National Science Foundation (3100A0-108102 and 310000-120791; Sinergia CRSIK0-122697 and CRISK0-122691), the Catalonia Ministry of Innovation, Universities and Enterprise (grant 2009 BE1 00402), the Spanish Ministry of Science and Innovation (grant Juan de la Cierva JCI-2008-2168), and intramural funding from the EPFL.

\section{References}

Abrous DN, Montaron MF, Petry KG, Rougon G, Darnaudery M, Le Moal M, Mayo W. 1997. Decrease in highly polysialylated neuronal cell adhesion molecules and in spatial learning during ageing are not correlated. Brain Res 744: 285-292.

Alfarez DN, Joels M, Krugers HJ. 2003. Chronic unpredictable stress impairs long-term potentiation in rat hippocampal CA1 area and dentate gyrus in vitro. Eur J Neurosci 17: 1928-1934.

Alfonso J, Frick LR, Silberman DM, Palumbo ML, Genaro AM, Frasch AC 2006. Regulation of hippocampal gene expression is conserved in two species subjected to different stressors and antidepressant treatments. Biol Psychiatry 59: 244-251.

Bahr BA, Godshall AC, Murray BA, Lynch G. 1993. Age-related changes in neural cell adhesion molecule (NCAM) isoforms in the mouse telencephalon. Brain Res 628: 286-292.

Barense MD, Fox MT, Baxter MG. 2002. Aged rats are impaired on an attentional set-shifting task sensitive to medial frontal cortex damage in young rats. Learn Mem 9: 191-201. 
Barnes CA. 1979. Memory deficits associated with senescence: A neurophysiological and behavioral study in the rat. J Comp Physiol Psychol 93: 74-104.

Barnes CA, McNaughton BL. 1980. Physiological compensation for loss of afferent synapses in rat hippocampal granule cells during senescence. $J$ Physiol 309: 473-485.

Beuzen A, Belzung C. 1995. Link between emotional memory and anxiety states: A study by principal component analysis. Physiol Behav 58: 111-118.

Bisaz R, Sandi C. 2010. The role of NCAM in auditory fear conditioning and its modulation by stress: A focus on the amygdala. Genes Brain Behav 9: 353-364.

Bisaz R, Sandi C. 2012. Vulnerability of conditional NCAM-deficient mice to develop stress-induced behavioral alterations. Stress 15: 195-206.

Bisaz R, Schachner M, Sandi C. 2011. Causal evidence for the involvement of the neural cell adhesion molecule, NCAM, in chronic stress-induced cognitive impairments. Hippocampus 21: 56-71.

Bloss EB, Janssen WG, Ohm DT, Yuk FJ, Wadsworth S, Saardi KM, McEwen BS, Morrison JH. 2011. Evidence for reduced experience-dependent dendritic spine plasticity in the aging prefrontal cortex. J Neurosci 31: 7831-7839.

Bloss EB, Puri R, Yuk F, Punsoni M, Hara Y, Janssen WG, McEwen BS, Morrison JH. 2013. Morphological and molecular changes in aging rat prelimbic prefrontal cortical synapses. Neurobiol Aging 34: 200-210.

Bukalo O, Fentrop N, Lee AY, Salmen B, Law JW, Wotjak CT, Schweizer M, Dityatev A, Schachner M. 2004. Conditional ablation of the neural cell adhesion molecule reduces precision of spatial learning, long-term potentiation, and depression in the CA1 subfield of mouse hippocampus. J Neurosci 24: 1565-1577.

Burke SN, Barnes CA. 2006. Neural plasticity in the ageing brain. Nat Rev Neurosci 7: 30-40.

Buttner B, Horstkorte R. 2010. Intracellular ligands of NCAM. Adv Exp Med Biol 663: $55-66$.

Cambon K, Hansen SM, Venero C, Herrero AI, Skibo G, Berezin V, Bock E, Sandi C. 2004. A synthetic neural cell adhesion molecule mimetic peptide promotes synaptogenesis, enhances presynaptic function, and facilitates memory consolidation. J Neurosci 24: 4197-4204.

Cerqueira JJ, Mailliet F, Almeida OF, Jay TM, Sousa N. 2007. The prefrontal cortex as a key target of the maladaptive response to stress. J Neurosci 27: $2781-2787$.

Chen G, Chen KS, Knox J, Inglis J, Bernard A, Martin SJ, Justice A, McConlogue L, Games D, Freedman SB, et al. 2000. A learning deficit related to age and $\beta$-amyloid plaques in a mouse model of Alzheimer's disease. Nature 408: 975-979.

Conboy L, Sandi C. 2010. Stress at learning facilitates memory formation by regulating AMPA receptor trafficking through a glucocorticoid action. Neuropsychopharmacology 35: 674-685.

Conboy L, Bisaz R, Markram K, Sandi C. 2010. Role of NCAM in emotion and learning. Adv Exp Med Biol 663: 271-296.

Conrad CD. 2010. A critical review of chronic stress effects on spatial learning and memory. Prog Neuropsychopharmacol Biol Psychiatry 34: $742-755$.

Dieguez D Jr, Barea-Rodriguez EJ. 2004. Aging impairs the late phase of long-term potentiation at the medial perforant path-CA3 synapse in awake rats. Synapse 52: 53-61.

Ditlevsen DK, Kolkova K. 2010. Signaling pathways involved in NCAM-induced neurite outgrowth. Adv Exp Med Biol 663: 151-168.

Donohue HS, Gabbott PL, Davies HA, Rodriguez JJ, Cordero MI, Sandi C, Medvedev NI, Popov VI, Colyer FM, Peddie CJ, et al. 2006. Chronic restraint stress induces changes in synapse morphology in stratum lacunosum-moleculare CA1 rat hippocampus: A stereological and three-dimensional ultrastructural study. Neuroscience 140: 597-606.

Driscoll I, Sutherland RJ. 2005. The aging hippocampus: Navigating between rat and human experiments. Rev Neurosci 16: 87-121.

Driscoll I, Howard SR, Stone JC, Monfils MH, Tomanek B, Brooks WM, Sutherland RJ. 2006. The aging hippocampus: A multi-level analysis in the rat. Neuroscience 139: 1173-1185.

Dumitriu D, Hao JD, Hara Y, Kaufmann J, Janssen WGM, Lou W, Rapp PR, Morrison JH. 2010. Selective changes in thin spine density and morphology in monkey prefrontal cortex correlate with age-related cognitive impairment. J Neurosci 30: 7507-7515.

Erickson CA, Barnes CA. 2003. The neurobiology of memory changes in normal aging. Exp Gerontol 38: 61-69.

Fox GB, Kennedy N, Regan CM. 1995. Polysialylated neural cell adhesion molecule expression by neurons and astroglial processes in the rat dentate gyrus declines dramatically with increasing age. Int J Dev Neurosci 13: 663-672.

Gerges NZ, Aleisa AM, Schwarz LA, Alkadhi KA. 2004. Reduced basal CaMKII levels in hippocampal CA1 region: Possible cause of stress-induced impairment of LTP in chronically stressed rats. Hippocampus 14: 402-410.
Hedden T, Gabrieli JDE. 2004. Insights into the ageing mind: A view from cognitive neuroscience. Nat Rev Neurosci 5: 87-U12.

Herrero AI, Sandi C, Venero C. 2006. Individual differences in anxiety trait are related to spatial learning abilities and hippocampal expression of mineralocorticoid receptors. Neurobiol Learn Mem 86: $150-159$.

Holmes A, Wellman CL. 2009. Stress-induced prefrontal reorganization and executive dysfunction in rodents. Neurosci Biobehav Rev 33: $773-783$.

Huang Q, Liu H, Zhu H, Zhou JN. 2008. Castration had no effect on decreased expression of the neural cell adhesion molecule in the prefrontal cortex of rats subjected to chronic mild stress. Int J Clin Exp Med 1: 310-318.

Jakobsson J, Cordero MI, Bisaz R, Groner AC, Busskamp V, Bensadoun JC, Cammas F, Losson R, Mansuy IM, Sandi C, et al. 2008. KAP1-mediated epigenetic repression in the forebrain modulates behavioral vulnerability to stress. Neuron 60: $818-831$.

Kiss JZ, Muller D. 2001. Contribution of the neural cell adhesion molecule to neuronal and synaptic plasticity. Rev Neurosci 12: 297-310.

Knafo S, Venero C, Sanchez-Puelles C, Pereda-Perez I, Franco A, Sandi C, Suarez LM, Solis JM, Alonso-Nanclares L, Martin ED, et al. 2012. Facilitation of AMPA receptor synaptic delivery as a molecular mechanism for cognitive enhancement. PLoS Biol 10: e1001262.

Kochlamazashvili G, Bukalo O, Senkov O, Salmen B, Gerardy-Schahn R, Engel AK, Schachner M, Dityatev A. 2012. Restoration of synaptic plasticity and learning in young and aged NCAM-deficient mice by enhancing neurotransmission mediated by GluN2A-containing NMDA receptors. J Neurosci 32: 2263-2275.

Kolata S, Light K, Grossman HC, Hale G, Matzel LD. 2007. Selective attention is a primary determinant of the relationship between working memory and general learning ability in outbred mice. Learn Mem 14: $22-28$.

Kolata S, Wu J, Light K, Schachner M, Matzel LD. 2008. Impaired working memory duration but normal learning abilities found in mice that are conditionally deficient in the close homolog of L1. J Neurosci $\mathbf{2 8}$ : $13505-13510$.

Kolkova K. 2010. Biosynthesis of NCAM. Adv Exp Med Biol 663: 213-225.

Lalonde R. 2002. The neurobiological basis of spontaneous alternation. Neurosci Biobehav Rev 26: 91-104.

Linnemann D, Gaardsvoll H, Olsen M, Bock E. 1993. Expression of NCAM mRNA and polypeptides in aging rat brain. Int J Dev Neurosci 11: $71-81$.

Liston C, Miller MM, Goldwater DS, Radley JJ, Rocher AB, Hof PR, Morrison JH, McEwen BS. 2006. Stress-induced alterations in prefrontal cortical dendritic morphology predict selective impairments in perceptual attentional set-shifting. I Neurosci 26: 7870-7874.

Magarinos AM, McEwen BS. 1995. Stress-induced atrophy of apical dendrites of hippocampal CA3c neurons: Comparison of stressors. Neuroscience 69: 83-88.

Maness PF, Schachner M. 2007. Neural recognition molecules of the immunoglobulin superfamily: Signaling transducers of axon guidance and neuronal migration. Nat Neurosci 10: 19-26.

McEwen BS. 2002. Sex, stress and the hippocampus: Allostasis, allostatic load and the aging process. Neurobiol Aging 23: 921-939.

McNaughton N. 1997. Cognitive dysfunction resulting from hippocampal hyperactivity-a possible cause of anxiety disorder? Pharmacol Biochem Behav 56: 603-611.

Morrison JH, Baxter MG. 2012. The ageing cortical synapse: Hallmarks and implications for cognitive decline. Nat Rev Neurosci 13: 240-250.

Muller D, Mendez P, Deroo M, Klauser P, Steen S, Poglia L. 2010. Role of NCAM in spine dynamics and synaptogenesis. Adv Exp Med Biol 663: $245-256$.

Nicholson DA, Yoshida R, Berry RW, Gallagher M, Geinisman Y. 2004. Reduction in size of perforated postsynaptic densities in hippocampal axospinous synapses and age-related spatial learning impairments. $J$ Neurosci 24: 7648-7653.

Ojo B, Rezaie P, Gabbott PL, Cowely TR, Medvedev NI, Lynch MA, Stewart MG. 2011. A neural cell adhesion molecule-derived peptide, FGL, attenuates glial cell activation in the aged hippocampus. Exp Neurol 232: 318-328.

Ojo B, Rezaie P, Gabbott PL, Davies H, Colyer F, Cowley TR, Lynch M, Stewart MG. 2012. Age-related changes in the hippocampus (loss of synaptophysin and glial-synaptic interaction) are modified by systemic treatment with an NCAM-derived peptide, FGL. Brain Behav Immun 26: $778-788$.

Panicker AK, Buhusi M, Thelen K, Maness PF. 2003. Cellular signalling mechanisms of neural cell adhesion molecules. Front Biosci 8: d900-d911.

Pavlides C, Nivon LG, McEwen BS. 2002. Effects of chronic stress on hippocampal long-term potentiation. Hippocampus 12: 245-257.

Peters A, Sethares C, Luebke JI. 2008. Synapses are lost during aging in the primate prefrontal cortex. Neuroscience 152: 970-981. 
Polo-Parada L, Bose CM, Plattner F, Landmesser LT. 2004. Distinct roles of different neural cell adhesion molecule (NCAM) isoforms in synaptic maturation revealed by analysis of NCAM $180 \mathrm{kDa}$ isoform-deficient mice. J Neurosci 24: 1852-1864.

Popov VI, Medvedev NI, Kraev IV, Gabbott PL, Davies HA, Lynch M, Cowley TR, Berezin V, Bock E, Stewart MG. 2008. A cell adhesion molecule mimetic, FGL peptide, induces alterations in synapse and dendritic spine structure in the dentate gyrus of aged rats: A three-dimensional ultrastructural study. Eur J Neurosci 27: 301-314.

Radley JJ, Sisti HM, Hao J, Rocher AB, McCall T, Hof PR, McEwen BS, Morrison JH. 2004. Chronic behavioral stress induces apical dendritic reorganization in pyramidal neurons of the medial prefrontal cortex. Neuroscience 125: 1-6.

Radley JJ, Rocher AB, Miller M, Janssen WG, Liston C, Hof PR, McEwen BS, Morrison JH. 2006. Repeated stress induces dendritic spine loss in the rat medial prefrontal cortex. Cereb Cortex 16: 313-320.

Ramos BP, Birnbaum SG, Lindenmayer I, Newton SS, Duman RS, Arnsten AF. 2003. Dysregulation of protein kinase a signaling in the aged prefrontal cortex: New strategy for treating age-related cognitive decline. Neuron 40: 835-845.

Rapp PR, Gallagher M. 1996. Preserved neuron number in the hippocampus of aged rats with spatial learning deficits. Proc Natl Acad Sci 93: 9926-9930.

Rosenzweig ES, Barnes CA. 2003. Impact of aging on hippocampal function: Plasticity, network dynamics, and cognition. Prog Neurobiol 69: $143-179$

Rowe WB, Spreekmeester E, Meaney MJ, Quirion R, Rochford J. 1998. Reactivity to novelty in cognitively-impaired and cognitively-unimpaired aged rats and young rats. Neuroscience 83: $669-680$.

Runyan JD, Moore AN, Dash PK. 2005. A role for prefrontal calcium-sensitive protein phosphatase and kinase activities in working memory. Learn Mem 12: 103-110.

Rutishauser U. 2008. Polysialic acid in the plasticity of the developing and adult vertebrate nervous system. Nat Rev Neurosci 9: 26-35.

Sandi C. 2004. Stress, cognitive impairment and cell adhesion molecules. Nat Rev Neurosci 5: 917-930.

Sandi C, Bisaz R. 2007. A model for the involvement of neural cell adhesion molecules in stress-related mood disorders. Neuroendocrinology 85: $158-176$.

Sandi C, Touyarot K. 2006. Mid-life stress and cognitive deficits during early aging in rats: Individual differences and hippocampal correlates. Neurobiol Aging 27: 128-140.

Sandi C, Merino JJ, Cordero MI, Touyarot K, Venero C. 2001. Effects of chronic stress on contextual fear conditioning and the hippocampal expression of the neural cell adhesion molecule, its polysialylation, and L1. Neuroscience 102: 329-339.

Sandi C, Davies HA, Cordero MI, Rodriguez JJ, Popov VI, Stewart MG. 2003. Rapid reversal of stress induced loss of synapses in CA3 of rat hippocampus following water maze training. Eur J Neurosci 17: $2447-2456$

Schuster T, Krug M, Stalder M, Hackel N, Gerardy-Schahn R, Schachner M. 2001. Immunoelectron microscopic localization of the neural recognition molecules L1, NCAM, and its isoform NCAM180, the NCAM-associated polysialic acid, $\beta 1$ integrin and the extracellular matrix molecule tenascin- $\mathrm{R}$ in synapses of the adult rat hippocampus. I Neurobiol 49: 142-158.

Seki T. 2002. Expression patterns of immature neuronal markers PSA-NCAM, CRMP-4 and NeuroD in the hippocampus of young adult and aged rodents. J Neurosci Res 70: 327-334.

Seki T, Arai Y. 1995. Age-related production of new granule cells in the adult dentate gyrus. Neuroreport 6: 2479-2482.

Smith TD, Adams MM, Gallagher M, Morrison JH, Rapp PR. 2000. Circuit-specific alterations in hippocampal synaptophysin immunoreactivity predict spatial learning impairment in aged rats. J Neurosci 20: 6587-6593.

Sousa N, Lukoyanov NV, Madeira MD, Almeida OF, Paula-Barbosa MM. 2000. Reorganization of the morphology of hippocampal neurites and synapses after stress-induced damage correlates with behavioral improvement. Neuroscience 97: 253-266.

Steele RJ, Morris RG. 1999. Delay-dependent impairment of a matching-to-place task with chronic and intrahippocampal infusion of the NMDA-antagonist D-AP5. Hippocampus 9: 118-136.

Stewart MG, Davies HA, Sandi C, Kraev IV, Rogachevsky VV, Peddie CJ, Rodriguez JJ, Cordero MI, Donohue HS, Gabbott PL, et al. 2005. Stress suppresses and learning induces plasticity in CA3 of rat hippocampus: A three-dimensional ultrastructural study of thorny excrescences and their postsynaptic densities. Neuroscience 131: 43-54.

Strekalova H, Buhmann C, Kleene R, Eggers C, Saffell J, Hemperly J, Weiller C, Muller-Thomsen T, Schachner M. 2006. Elevated levels of neural recognition molecule $\mathrm{L} 1$ in the cerebrospinal fluid of patients with Alzheimer disease and other dementia syndromes. Neurobiol Aging 27: 1-9.

Tereshchenko Y, Morellini F, Dityatev A, Schachner M, Irintchev A. 2011. Neural cell adhesion molecule ablation in mice causes hippocampal dysplasia and loss of septal cholinergic neurons. J Comp Neurol 519: 2475-2492.

Theodosis DT, Schachner M, Neumann ID. 2004. Oxytocin neuron activation in NCAM-deficient mice: Anatomical and functional consequences. Eur J Neurosci 20: 3270-3280.

Touyarot K, Venero C, Sandi C. 2004. Spatial learning impairment induced by chronic stress is related to individual differences in novelty reactivity: Search for neurobiological correlates. Psychoneuroendocrinology 29: 290-305.

van der Staay FJ. 2002. Assessment of age-associated cognitive deficits in rats: A tricky business. Neurosci Biobehav Rev 26: 753-759.

Varea E, Castillo-Gomez E, Gomez-Climent MA, Guirado R, Blasco-Ibanez JM, Crespo C, Martinez-Guijarro FJ, Nacher J. 2009. Differential evolution of PSA-NCAM expression during aging of the rat telencephalon. Neurobiol Aging 30: 808-818.

Venero C, Tilling T, Hermans-Borgmeyer I, Schmidt R, Schachner M, Sandi C. 2002. Chronic stress induces opposite changes in the mRNA expression of the cell adhesion molecules NCAM and L1. Neuroscience 115: $1211-1219$.

Venero C, Herrero AI, Touyarot K, Cambon K, Lopez-Fernandez MA, Berezin V, Bock E, Sandi C. 2006. Hippocampal up-regulation of NCAM expression and polysialylation plays a key role on spatial memory. Eur J Neurosci 23: 1585-1595.

Walmod PS, Kolkova K, Berezin V, Bock E. 2004. Zippers make signals: NCAM-mediated molecular interactions and signal transduction. Neurochem Res 29: 2015-2035.

Watanabe Y, Gould E, Cameron HA, Daniels DC, McEwen BS. 1992. Phenytoin prevents stress- and corticosterone-induced atrophy of CA3 pyramidal neurons. Hippocampus 2: 431-435.

Wietrzych M, Meziane H, Sutter A, Ghyselinck N, Chapman PF, Chambon P, Krezel W. 2005. Working memory deficits in retinoid X receptor $\gamma$-deficient mice. Learn Mem 12: 318-326.

Yamada M, Chiba T, Sasabe J, Nawa M, Tajima H, Niikura T, Terashita K, Aiso S, Kita Y, Matsuoka M, et al. 2005. Implanted cannula-mediated repetitive administration of $\alpha \beta 25-35$ into the mouse cerebral ventricle effectively impairs spatial working memory. Behav Brain Res 164: 139-146.

Yoon T, Okada J, Jung MW, Kim JJ. 2008. Prefrontal cortex and hippocampus subserve different components of working memory in rats. Learn Mem 15: 97-105.

Zeng H, Chattarji S, Barbarosie M, Rondi-Reig L, Philpot BD, Miyakawa T, Bear MF, Tonegawa S. 2001. Forebrain-specific calcineurin knockout selectively impairs bidirectional synaptic plasticity and working/ episodic-like memory. Cell 107: 617-629.

Zhang M, Moon C, Chan GC, Yang L, Zheng F, Conti AC, Muglia L, Muglia LJ, Storm DR, Wang H. 2008. Ca-stimulated type 8 adenylyl cyclase is required for rapid acquisition of novel spatial information and for working/episodic-like memory. J Neurosci 28: 4736-4744.

Received December 16, 2012; accepted in revised form January 10, 2013. 


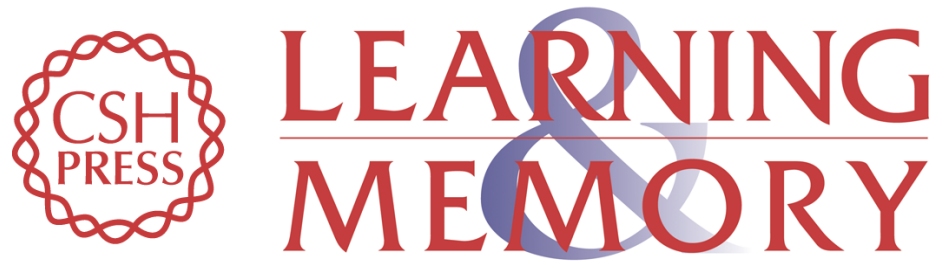

\section{Age-related cognitive impairments in mice with a conditional ablation of the neural cell adhesion molecule}

Reto Bisaz, Pere Boadas-Vaello, David Genoux, et al.

Learn. Mem. 2013, 20:

Access the most recent version at doi:10.1101/Im.030064.112

Supplemental
Material http://learnmem.cshlp.org/content/suppl/2013/03/13/20.4.183.DC1

References This article cites 94 articles, 18 of which can be accessed free at: http://learnmem.cshlp.org/content/20/4/183.full.html\#ref-list-1

License

Email Alerting Receive free email alerts when new articles cite this article - sign up in the box at the Service top right corner of the article or click here. 